\title{
Demyelinating central nervous system lesions, following the use of tumor necrosis factor alpha antagonist
}

\author{
Emmanuel Bogdos ${ }^{1}$, Sofia Markoula', Anastasia Zikou ${ }^{2}$, Paraskevi Voulgari ${ }^{3}$, Aleksandros Drosos ${ }^{3}$, \\ Spyridon Konitsiotis ${ }^{1}$
}

\begin{abstract}
'Department of Neurology, Univeristy Hospital of loannnina, loannina 45500, Greece. 2Department of Radiology, Univeristy Hospital of loannnina, loannina 45500, Greece.

${ }^{3}$ Department of Rheumatology, Univeristy Hospital of loannnina, loannina 45500, Greece.
\end{abstract}

Correspondence to: Dr. Emmanuel Bogdos, Department of Neurology, Univeristy Hospital of loannnina, loannina 45500, Greece. E-mail: manosbogdos@gmail.com

How to cite this article: Bogdos E, Markoula S, Zikou A, Voulgari P, Drosos A, Konitsiotis S. Demyelinating central nervous system lesions, following the use of tumor necrosis factor alpha antagonist. Neuroimmuno/ Neuroinflammation 2018;5:19.

http://dx.doi.org/10.20517/2347-8659.2018.07

Received: 26 Feb 2018 First Decision: 7 Mar 2018 Revised: 26 Mar 2018 Accepted: 26 Mar 2018 Published: 22 May 2018

Science Editor: Athanassios P. Kyritsis Copy Editor: Jun-Yao Li Production Editor: Huan-Liang Wu

\begin{abstract}
Tumor necrosis factor alpha (TNF $\alpha$ ) antagonists have been a valuable tool in treating patients with rheumatoid arthritis (RA), but reports and case series of neurological adverse events due to TNF $\alpha$ antagonists have been reported. Furthermore, central nervous system (CNS) lymphoma always remains a remote, yet a worrisome complication in RA patients, especially in those under treatment with methotrexate (MTX). We present a female patient with RA with tumor-like active demyelinating lesions attributed to TNF $\alpha$ antagonist, confirmed by an FNA biopsy, otherwise clinically and radiologically challenging to distinguish from CNS lymphoma. A 72-year-old female patient with RA under TNF $\alpha$ antagonist and MTX treatment was presented with neurological symptoms and signs. The brain MRI revealed four tumor-like contrast-enhancing lesions bilaterally, the demyelinating nature of which was delineated by the FNA biopsy. A full clinical and radiological recovery was achieved after the TNF $\alpha$ antagonist was permanently withdrawn. Patients with RA under anti-TNF agents and MTX are predisposed to complications such as CNS lymphoma and CNS demyelination. This case uniquely highlights the physicians' vigilance in pursuing these complications and the usage of the FNA when tumor-like appearances on the brain MRI convolute the final diagnosis.
\end{abstract}

Keywords: Anti-tumor necrosis factor complications, demyelination, rheumatoid arthritis

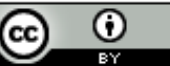

(C) The Author(s) 2018. Open Access This article is licensed under a Creative Commons Attribution 4.0 International License (https://creativecommons.org/licenses/by/4.0/), which permits unrestricted use sharing, adaptation, distribution and reproduction in any medium or format, for any purpose, even commercially, as long as you give appropriate credit to the original author(s) and the source, provide a link to the Creative Commons license, and indicate if changes were made. 


\section{INTRODUCTION}

Tumor necrosis factor alpha $(\mathrm{TNF} \alpha)$ antagonists represent a revolutionary therapeutic choice for many inflammatory diseases such as rheumatoid arthritis (RA) $)^{[1,2]}$. Although they are generally considered as a low-risk intervention, critical side effects of their use may develop that require awareness and prompt action, such as instant discontinuation of TNF $\alpha$ antagonists. Furthermore, RA patients have a high risk of a sitespecific lymphoma regardless of the lymphoma type ${ }^{[3]}$.

We present a case of RA treated with TNF $\alpha$ antagonists and methotrexate (MTX), with tumor-like activedemyelinating brain lesions effectively confirmed by an FNA biopsy, as it is both clinically and radiologically challenging to differentiate from central nervous system (CNS) lymphoma.

\section{CASE REPORT}

A 72-year-old woman, with a diagnosis of rheumatoid arthritis for the past 18 years, was admitted to the Department of Neurology at the University Hospital of Ioannina with symptoms of dizziness, headache and walking instability, that gradually developed in the last week before her admission. The patient has been receiving treatment with TNF $\alpha$ antagonist (etanercept) and MTX for the last 18 months.

The patient underwent a complete physical examination and a detailed neurological evaluation which included both lumbar puncture and brain magnetic resonance imaging (MRI). The patient had mild left hemiparesis and ataxia. The lumbar puncture showed a normal cerebrospinal fluid (CSF) cell count, a mild elevation in CSF protein levels (57 mg/dL) and an elevated CSF IgG index (0.857). CSF was negative for malignant cells.

The brain MRI showed bilateral contrast-enhancing lesions in the cerebral hemispheres with moderate perilesional edema and enhancement [Figure 1]. Because malignant lymphoma was considered first in the differential diagnosis, no corticosteroids were administered and the patient was promptly referred for an FNA biopsy. The histological examination, which included luxol fast blue staining, showed findings compatible with lesions of demyelinating nature. The anti-TNF agent was considered as a potential causative factor for the demyelination, thus was withdrawn from the patient. No other treatment was initiated.

The patient, who has eventually been placed on interferon, was followed up every 2 to 3 months with appropriate laboratory monitoring, as well as with complete physical and neurological examinations. An MRI was repeated after a mean period of 6 months. Symptoms were completely resolved in 2 months with a dramatic retrieval of the imaging findings [Figure 2].

\section{DISCUSSION}

This is the first case, to our knowledge, to show that an FNA biopsy has differentiated brain demyelination from CNS lymphoma in an RA patient, treated with TNF $\alpha$ antagonist and MTX. The TNF $\alpha$ antagonist was considered as the causative factor for the demyelinating lesions, which were resolved by withdrawing the medication.

Many adverse events, due to TNF $\alpha$ antagonists, have been published, including central nervous and peripheral nervous system demyelination, transverse myelitis, retrobulbar optic neuritis and more ${ }^{[4-6]}$. The mechanism of this demyelination is not perfectly outlined, since it is not certain whether anti-TNF $\alpha$ blockers unmask pre-existing demyelinating disorders or induce de novo demyelination of the CNS and peripheral nervous system ${ }^{[1,7]}$.

In a French national survey ${ }^{[5]}$, demyelination occurred in a median period of 10.2 months after treatment initiation, while etanercept was the reported agent in the majority of cases of CNS involvement ${ }^{[8]}$. Of interest 

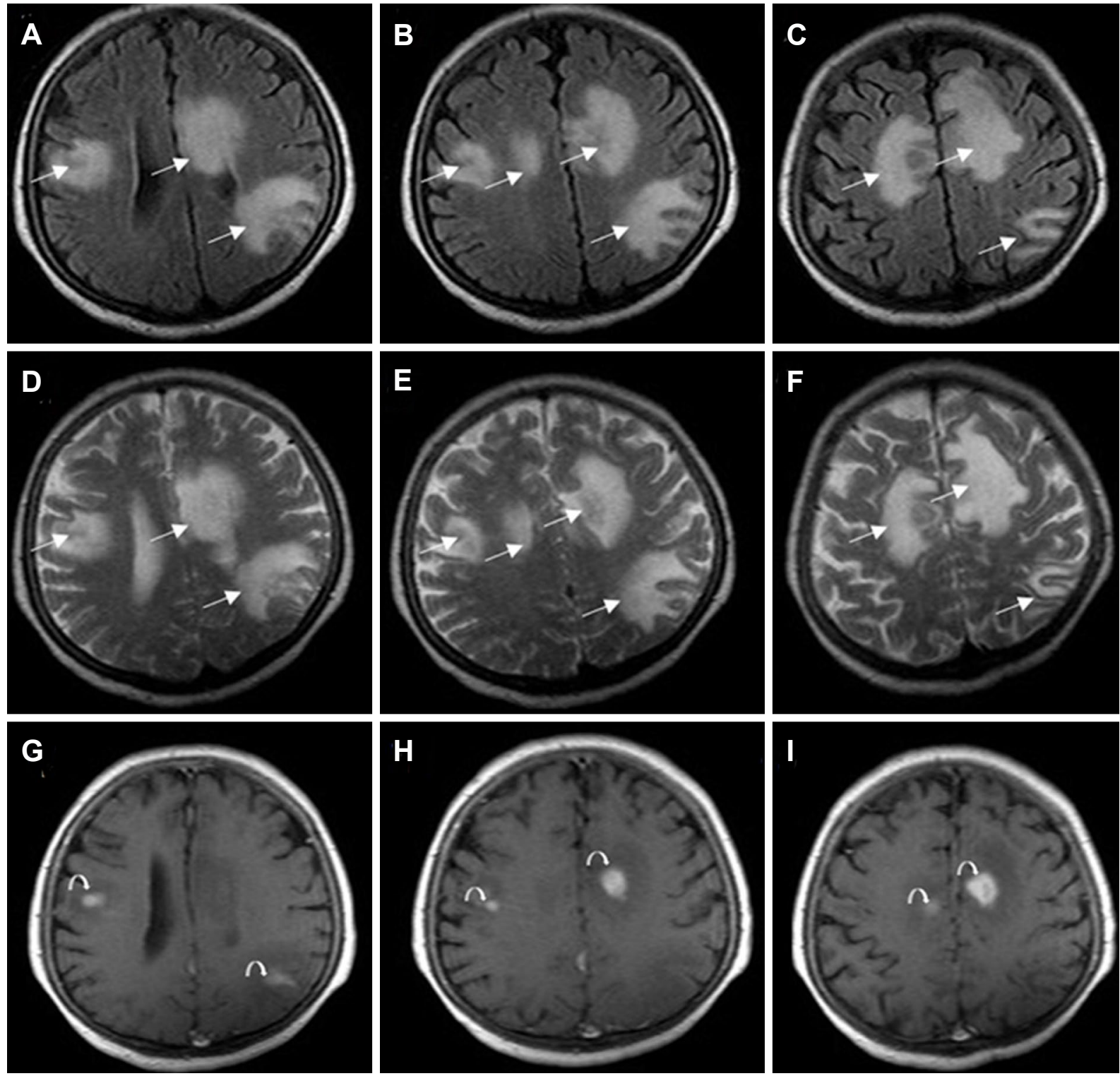

Figure 1. Axial fluid-attenuated inversion recovery (A-C) and T2-weighted (D-F) images show multiple large juxtacortical and periventricular hyperintense lesions (arrows). Axial post-contrast T1-weighted images (G-I) demonstrate that the lesions abnormally enhance, suggesting an active demyelinating process (curved arrows)

is the fact that, in most reported cases, the chronology of clinical events is suggestive of a causal relationship between anti-TNF $\alpha$ and induction of demyelination, but only few cases have shown a definite positive relationship, proven by rechallenge after re-admission of anti-TNF agents ${ }^{[5]}$. There is only one report in the literature of demyelinating lesions ${ }^{[9]}$, that is proven to be demyelinating after craniectomy and biopsy.

It is well known that patients with certain autoimmune and inflammatory disorders, such as RA, have an increased risk of developing malignant lymphoma ${ }^{[10]}$ with an overall two-fold increase in lymphoma risk compared with the general population ${ }^{[3]}$. The possible mechanisms for this increased risk include the fact that RA results in persistent immunologic stimulation (which may lead to clonal selection and predispose CD5+ $\mathrm{B}$ cells to malignant transformation), and decreased number and function of T-suppressor lymphocytes ${ }^{[3]}$.

Furthermore, mature T/NK-cell lymphoproliferative diseases development is a frequent complication in RA patients treated with $\mathrm{MTX}^{[11]}$, which additionally may shorten the interval between the diagnosis of RA and 

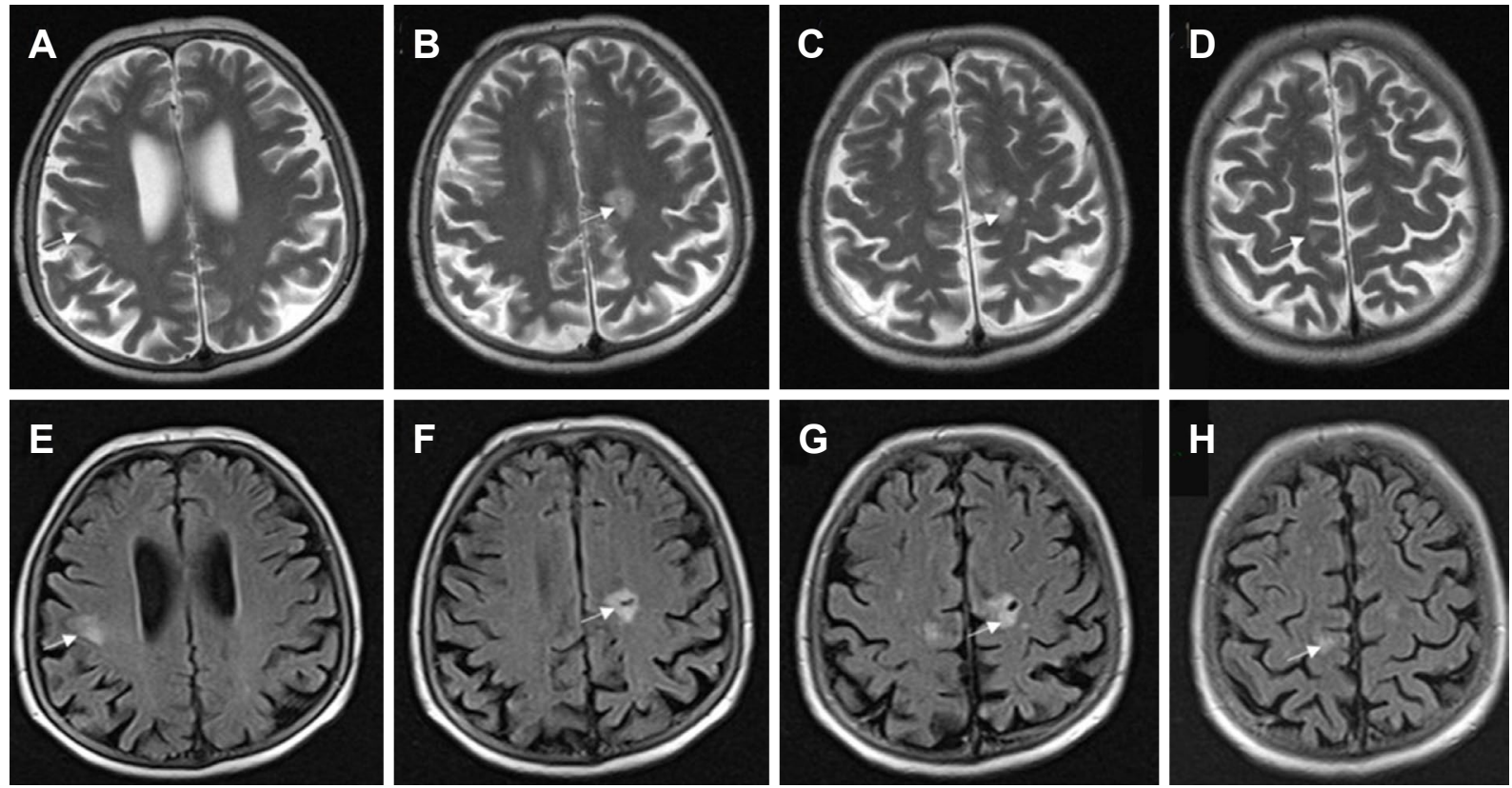

Figure 2. Follow up magnetic resonance imaging after 3 months. Axial T2-weighted (A-D) and fluid-attenuated inversion recovery (E-H) images reveal significant remission of the lesions (arrows)

lymphoma development when compared with that in MTX-naive RA patients ${ }^{[12]}$.

Conclusively, in patients with RA treated with TNF $\alpha$ antagonists and MTX, both lymphoma and CNS demyelination may rarely occur. Patients with RA should benefit from a follow-up, including a brain MRI ${ }^{[7]}$. Since brain imaging findings of lymphoma and CNS demyelination often share similarities, especially in tumor-like active-demyelinating lesions, their distinction may prove to be challenging ${ }^{[9]}$. An FNA biopsy could be recommended in these cases, before proceeding any further with a craniotomy. Luxol fast blue staining (which is not routinely included in tumor histological protocols) should be requested to detect the potential demyelinating nature of the lesion ${ }^{[13]}$.

\section{DECLARATIONS}

\section{Acknowledgments}

The authors heartily thank Ms. Alexandra Bitza and Ms. Suyeon Lee for polishing the language of the manuscript.

\section{Authors' contributions}

Data collection: Bogdos E

Data accuracy and integrity: Drosos A

Drafting: Bogdos E, Markoula S

Revising manuscript: Bogdos E, Markoula S, Zikou A, Voulgari P

Providing guidance and connecting all authors: Markoula S

Approval of final version of manuscript: Konitsiotis S

\section{Financial support and sponsorship}

None.

\section{Conflicts of interest}

The authors declared that there are no conflicts of interest. 


\section{Patient consent}

Informed consent was obtained from the patient.

\section{Ethics approval}

Not applicable.

\section{Copyright}

(C) The Author(s) 2018.

\section{REFERENCES}

1. Kemanetzoglou E, Andreadou E. CNS demyelination with TNF- $\alpha$ blockers. Curr Neurol Neurosci Rep 2017;17:36.

2. Filippini M, Bazzani C, Atzeni F, Sarzi Puttini P, Marchesoni A, Favalli EG, Caporali R, Cavagna L, Gorla R. Effects of anti-TNF alpha drugs on disability in patients with rheumatoid arthritis: long-term real-life data from the Lorhen Registry. Biomed Res Int 2014;2014:416892.

3. Smitten AL, Simon TA, Hochberg MC, Suissa S. A meta-analysis of the incidence of malignancy in adult patients with rheumatoid arthritis. Arthritis Res Ther 2008;10:R45.

4. Kaltsonoudis E, Zikou AK, Voulgari PV, Konitsiotis S, Argyropoulou MI, Drosos AA. Neurological adverse events in patients receiving anti-TNF therapy: a prospective imaging and electrophysiological study. Arthritis Res Ther 2014;16:R125.

5. Seror R, Richez C, Sordet C, Rist S, Gossec L, Direz G, Houvenagel E, Berthelot JM, Pagnoux C, Dernis E, Melac-Ducamp S, Bouvard B, Asquier C, Martin A, Puechal X, Mariette X; Club Rhumatismes et Inflammation Section of the SFR. Pattern of demyelination occurring during anti-TNF- $\alpha$ therapy: a French national survey. Rheumatology (Oxford) 2013;52:868-74.

6. Bosch X, Saiz A, Ramos-Casals M; BIOGEAS Study Group. Monoclonal antibody therapy-associated neurologic disorders. Nat Rev Neurol 2011;7:165-72.

7. Fromont A, De Seze J, Fleury MC, Maillefert JF, Moreau T. Inflammatory demyelinating events following treatment with anti-tumor necrosis factor. Cytokine 2009;45:55-7.

8. Solomon AJ, Spain RI, Kruer MC, Bourdette D. Inflammatory neurological disease in patients treated with tumor necrosis factor alpha inhibitors. Mult Scler 2011;17:1472-87.

9. Cereda CW, Zecca C, Mazzucchelli L, Valci L, Staedler C, Bassetti CL, Gobbi C. Tumefactive demyelinating lesions during etanercept treatment requiring decompressive hemicraniectomy. Mult Scler 2013;19:820-3.

10. Baecklund E, Smedby KE, Sutton LA, Askling J, Rosenquist R. Lymphoma development in patients with autoimmune and inflammatory disorders--what are the driving forces? Semin Cancer Biol 2014;24:61-70.

11. Kondo S, Tanimoto K, Yamada K, Yoshimoto G, Suematsu E, Fujisaki T, Oshiro Y, Tamura K, Takeshita M, Okamura S. Mature T/NKcell lymphoproliferative disease and Epstein-Barr virus infection are more frequent in patients with rheumatoid arthritis treated with methotrexate. Virchows Arch 2013;462:399-407.

12. Hoshida Y, Xu JX, Fujita S, Nakamichi I, Ikeda J, Tomita Y, Nakatsuka S, Tamaru J, Iizuka A, Takeuchi T, Aozasa K. Lymphoproliferative disorders in rheumatoid arthritis: clinicopathological analysis of 76 cases in relation to methotrexate medication. $J$ Rheumatol 2007;34:322-31

13. Fallah A, Sarfaraz B, Shanil E, John E. Paulseth, Paulseth JE, Jha NK. Case Series: tumefactive demyelinating lesions: a diagnostic challenge. Can J Surg 2010;53:69-70. 